Universidade de Brasília

Centro de Excelência em Turismo

\title{
UMA VISÃO DA MOTIVAÇÃO PARA O TRABALHO A PARTIR DO ESTUDO DE CASO DA EMPRESA X DO RAMO DE ALIMENTOS E BEBIDAS NO DISTRITO FEDERAL.
}

Fernanda Vieira Curvello

Dra. Deis Siqueira.

Monografia apresentada ao Centro de Excelência em Turismo da Universidade de Brasília como requisito parcial para obtenção do certificado de Especialista em Gestão da Hospitalidade.

Brasília, DF, Janeiro 2004. 


\author{
UNIVERSIDADE DE BRASÍLIA \\ Centro de Excelência em Turismo \\ Curso de Especialização em Gestão da Hospitalidade
}

\title{
UMA VISÃO DA MOTIVAÇÃO PARA O TRABALHO A PARTIR DO ESTUDO DE CASO DA EMPRESA X DO RAMO DE ALIMENTOS E BEBIDAS NO DISTRITO FEDERAL.
}

Fernanda Vieira Curvello

Dra. Deis Siqueira.

Brasília, DF, Janeiro 2004. 
Fernanda Vieira Curvello

\section{UMA VISÃO DA MOTIVAÇÃO PARA O TRABALHO A PARTIR DO ESTUDO DE CASO DA EMPRESA X DO RAMO DE ALIMENTOS E BEBIDAS NO DISTRITO FEDERAL.}

Banca Examinadora

Prof. Orientador: Assinatura:

Prof. Instituição: Assinatura:

Prof. Instituição: Assinatura:

Local:

Data: 


\section{DEDICATÓRIA}

A meus pais Célia e Pedro Paulo. E em especial à Cristina e à Márcia. 


\section{AGRADECIMENTOS}

Agradeço a Deus por ter me abençoado me privilegiando com uma família feliz e saudável. Um estágio maravilhoso, o qual, tive que superar alguns obstáculos, mas também obtive algumas recompensas. Agradeço também a todos que se dispuseram a me auxiliar direta e indiretamente na realização deste trabalho. 


\section{RESUMO}

Motivação, para muitos estudiosos é mais fácil dizer o que não é do que classificá-la. Fundamentada na Teoria de Maslow é possível obter um conhecimento teórico a respeito do complexo significado de motivação e a importância de fazer um levantamento das necessidades.

palavras-chave: motivação, necessidade, estudo de caso. 


\section{ABSTRACT}

Motivation, for many scholars, is easier to say what it is not of that it classifies it. Based on the Theory of Maslow, it is possible to get a theoretical knowledge regarding the comples meant of motivation

Key-words: motivation, necessity, case study. 


\section{SUMÁRIO}

1 MOTIVAÇÃO ........................................................................................................ 9

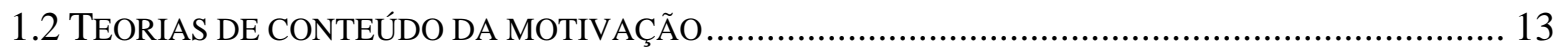

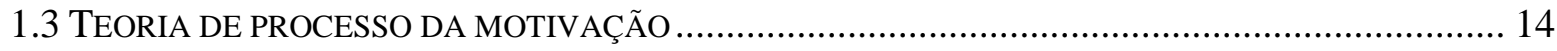

2 LEVANTAMENTO DE NECESSIDADES ........................................................................... 18

2.1 PESQUISA DESTINADA A TESTAR A HIERARQUIA DAS NECESSIDADES .................................. 25

3 METODOLOGIA.............................................................................................................................. 27

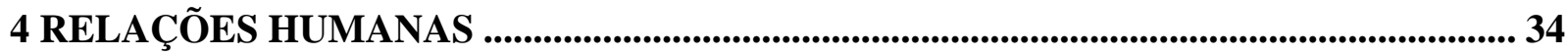

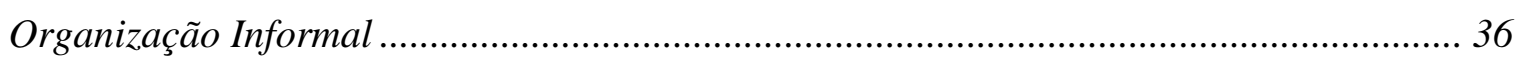

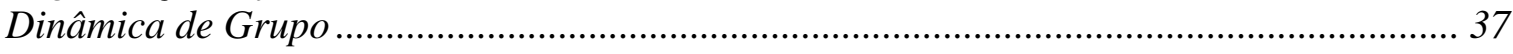

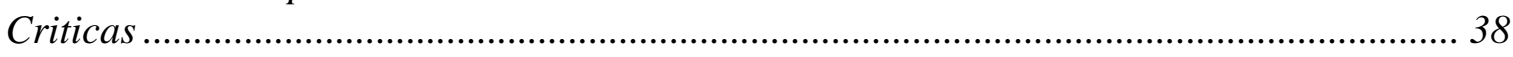

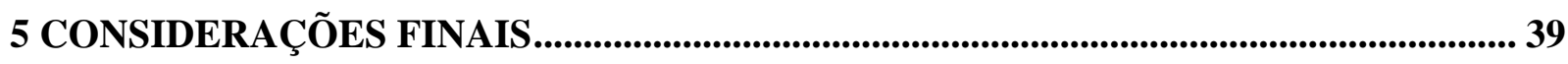

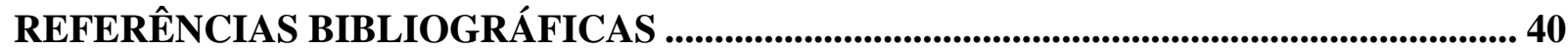




\section{INTRODUÇÃO}

A motivação nas empresas tem sido alvo de diversos estudos. O que é que leva realmente as pessoas a estarem motivadas e mais produtivas? A grande parte dos gestores tenta encontrar resposta para esta questão. Só depois de se conhecerem as fontes de motivação dos trabalhadores é que se podem esperar ganhos adicionais, efetuando, ao mesmo tempo, uma eficaz gestão de recursos humanos. O sucesso de qualquer organização passa sem dúvida pelo nível de motivação dos seus colaboradores. Afinal, o que é que leva os trabalhadores a continuarem ligados à empresa, seguindo as regras e convicções da mesma?

As empresas que de alguma maneira já conseguiram descobrir a origem da motivação dos seus colaboradores, devem trabalhar no sentido de a manter e incrementar, de forma a maximizar as potencialidades do seu mais importante recurso: as pessoas. 


\section{MOTIVAÇÃO}

Podemos considerar que ao longo dos anos torna-se crescente a ênfase dada ao estudo de temas relacionados à motivação, no entanto tais estudos partem de diferentes pontos de vista, tornando-se difícil definir de forma simplificada o conceito de motivação.

O pesquisador DAVIDOFF (1983), faz uma breve introdução do contexto histórico de motivação, o qual teve início com o cientista do comportamento William McDougall, fez com que no início do século $X X$ tornasse os motivos importantes em psicologia. Os motivos são denominados instintos, que tem como definição "forças irracionais, compulsórias, herdadas, que dão forma a tudo o que as pessoas fazem, sentem, percebem e pensam" (1983, p.385). No início outros psicólogos concordaram com a opinião de McDougall e trabalharam em prol da identificação de instintos específicos, tais como curiosidade, fome, fuga, fome, agressão, entre outros. Porém cientistas do comportamento insatisfeitos com a breve lista começaram a citar inúmeros outros instintos.

Devido a esse ocorrido os psicólogos de hoje em dia estão mais preocupados em enfocar a descrição e a explicação das influências sobre o comportamento motivado. Assim os teóricos da administração passaram a buscar na psicologia as bases de estudo para a compreensão do conceito de motivação para então aplicá-lo ao contexto organizacional. Neste sentido podemos identificar que boa parte dos desenvolvimentos teóricos tem como ponto de partida a teoria desenvolvida por Abraham Maslow que associa motivação a uma hierarquia de necessidades. 
Conforme CLONINGER (1999), Abraham Maslow, queria propor uma terceira força psicológica humanista que seria menos determinista e mais centrada em valores do que a psicanálise ou o behaviorismo. Propunha que as pessoas se desenvolvem através de cinco níveis de hierarquia de necessidades: fisiológico, segurança, amor e pertencimento, estima e auto-realização. Nos quatro estágios inferiores, a pessoa é motivada por deficiências. No estágio mais elevado, a auto-realização, a pessoa é motivada por motivações existenciais e tem características distintas, a principal das quais é a criatividade. Experiências supremas estados místicos de consciência particularmente comuns entre as pessoas auto-realizadas.

O autor recomendava à psicologia preocupar-se mais com os valores humanos, criticava a psicologia dominante por ser centrada no método, e não no problema, e afirmava que a investigação científica dos potenciais humanos mais elevados exigia o desenvolvimento de novos modelos de ciência.

Os psicólogos utilizam termos como: motivo, necessidade, impulso, e instinto para explicar o comportamento, que não pode ser diretamente observado ou medido. $\mathrm{O}$ termo necessidade é utilizado para demonstrar deficiências em requisitos corporais ou aprendidos ou em alguma combinação de ambos. O termo motivo, ou motivação, utilizada quando ocorre uma necessidade interna, despertando um comportamento para cumpri-la. As satisfações das necessidades fisiológicas básicas são os impulsos. E o termo instinto, ou padrão de ação fixa, refere-se às necessidades fisiológicas e aos padrões de comportamento que são influenciados tanto por fatores genéticos como ambientais.

Maslow não acreditava plenamente nos métodos científicos tradicionais, dizia que ao invés de esclarecer acaba por impedir o conhecimento da natureza humana ele acreditava que o homem poderia ir além dos seus processos primitivos. Apesar de termos necessidades de alimentação, reprodução e aprendizado, como os animais. 
O pesquisador Maslow fazia críticas nas teorias que se baseavam em pessoas neuróticas ou com grupos de pessoas que não estavam saudáveis. "A saúde é mais do que a ausência de doença ou de algum distúrbio" (1999 p. 488). A metodologia científica tradicional é centrada no método. E as experiências humanas que não podem ser estudadas pelo método tradicional recebem o nome de não-científicas, ao invés disso, o autor incentivava e recomendava a uma metodologia centrada no problema, os temas a serem estudados tem prioridade sobre os métodos.

$\mathrm{Na}$ verdade, não utilizar os métodos científicos tradicionais serveria apenas para complementá-los com o que as pessoas vivenciavam subjetivamente. Porém não é adequada, nem aconselhável a aplicação do conhecimento experiencial isoladamente da metodologia científica.

Toda essa teoria de Maslow pode ser aplicada em diversas áreas, já que seu interesse era aperfeiçoar a condição humana.

(...) essas aplicações fazem parte do movimento pelo potencial humano, que procura aperfeiçoar a condição humana estimulando o desenvolvimento dos indivíduos rumo aos seus potenciais mais elevados por meio de centros especiais e pela transformação de instituições sociais como os locais de trabalho e as escolas (CLONINGER, 1999, p. 506-7).

A hierarquia das necessidades tornou-se um conceito central para os psicólogos industrial-organizacionais. Onde trabalhadores são mais eficientes quando funcionam no nível das necessidades mais elevadas. Inversamente, o local de trabalho é uma das principais áreas de desenvolvimento da auto-realização.

Constatou-se que muitos empresários eram parecidos com os seus auto-realizadores, entre os executivos auto-realizados, encontrou relações interpessoais positivas e estimulantes com os subordinados e um trabalho mais produtivo e criativo. Infelizmente, muitos executivos não são auto-realizados, mas motivados por necessidades neuróticas de poder. O desafio, para as empresas, é preencher os cargos executivos com os 
indivíduos mais altamente desenvolvidos, pois as pessoas auto-realizadas não costumam ser particularmente atraídas por tais posições.

Seguindo a linha de pensamento e estudos Chiavenato em 1999, disse ser mais simples esclarecer o que não é motivação, pois para muitos a motivação se relaciona com preguiça, humor, boa vontade, o que o autor considera uma avaliação errada. $A$ motivação pode variar em um único indivíduo em níveis de necessidades diferentes e de acordo com o tempo, momento e situação que cada indivíduo está passando, vivendo.

A relação da motivação com três aspectos:

-a direção do comportamento (objetivo);

-a força e intensidade do comportamento (esforço);

-a duração e persistência do comportamento (necessidade) (CHIAVENATO, 1999, p.592).

A motivação é um processo contínuo de satisfação de necessidades individuais. A necessidade pode ser definida como uma carência interna da pessoa. O organismo, de uma pessoa está constantemente em busca de equilíbrio, mas sempre que surge uma necessidade, este equilíbrio é rompido. O indivíduo irá se esforçar, gerando uma tensão para suprir tal necessidade, quando satisfeita essa tensão irá ser aliviada. É conhecido como ciclo motivacional, pois sempre que houver uma carência haverá uma necessidade de satisfazê-la, quando alcançada voltará ao estado de equilíbrio.

Dentre tudo que foi citado e esclarecido sobre todo processo humano de motivar ou ser motivado para qualquer situação da sua vida e trabalho, podemos observar que a prática deste processo é de fato mais complexa sofre uma ação incondicional do indivíduo, não há um programa dentro de cada indivíduo para controlar ou administrar seus estímulos de estar ou não motivado para suas tarefas diárias. 


\subsection{Teorias de conteúdo da motivação}

Para Chiavenato (1999), as teorias de conteúdo se preocupam com as necessidades e incentivos que geram o comportamento, dentre elas existem duas teorias, porém são questionadas a respeito de sua validade, mas é a melhor forma de explicar a motivação das pessoas. Teoria da hierarquia das necessidades e a outra é a teoria motivaçãohigiene.

\section{$\underline{\text { Teoria da Hierarquia das Necessidades }}$}

Essa teoria foi apresentada por Maslow, a respeito da motivação humana. Porém Chiavenato (1999) faz uma comparação, entre a satisfação fora do trabalho com a satisfação dentro do trabalho, utilizando a pirâmide das hierarquias de necessidades de Maslow. Mostrando quais seriam os níveis de necessidade dentro de uma organização.

\section{$\underline{\text { Teoria dos Dois Fatores }}$}

Essa teoria foi proposta por Frederick Herzberg. Divide-se em dois fatores os higiênicos ou insatisfacientes, estes envolvem salário, políticas e diretrizes da organização, estilo de supervisão, condições ambientais de trabalho, segurança no emprego e relação com o superior, colegas e os subordinados, e os fatores motivacionais ou satisfacientes, que representam responsabilidade, crescimento e progresso e realização pessoal, satisfação no trabalho. Está voltado para o comportamento no trabalho, podendo ser utilizado como um instrumento pelo gestor.

\section{$\underline{\text { Teoria ERC }}$}

Alderfer modifica e simplifica a teoria de Maslow. Essa teoria reduz de cinco para três as necessidades básicas, que são elas: existência, relacionamento e crescimento. 
Outro aspecto em que a teoria ERC se diferencia da de Maslow, pois a segunda segue uma hierarquia de necessidades, quando uma necessidade mais baixa é suprida é que se pode migrar para uma superior, há uma progressão rígida já a teoria ERC é mais flexível.

O terceiro e último aspecto mostram que na teoria de Maslow o indivíduo é capaz de ter uma única necessidade por vez, e a teoria ERC diz o contrário, o indivíduo pode despertar mais de uma necessidade de uma única vez.

\section{Teoria das Necessidades Aprendidas}

McClelland focaliza três necessidades básicas, as quais, o indivíduo aprende e adquire através de experiências ao longo da vida de cada um. São elas: realização, poder e afiliação.

\subsection{Teoria de processo da motivação}

Chiavenato (1999), há quatro teorias, as quais são importantes para compreender o processo comportamental, como ele é ativado, dirigido, mantido e encerrado.

\section{$\underline{\text { Teoria do Estabelecimento de Objetivos }}$}

Edwin Locke e outros estudaram sobre o estabelecimento de objetivos, estes são fontes de motivação. Os objetivos podem influenciar o comportamento das pessoas. $\mathrm{O}$ estabelecimento de objetivos pode orientar no comportamento do indivíduo, os objetivos são também uma fonte motivadora, desde que não sejam objetivos impossíveis de se alcançar, sem especificidade. Cita ainda quatro métodos para motivar: 
- Dinheiro. Contudo, o dinheiro não deve ser o único motivador, mas aplicado juntamente com outros três métodos.

- Estabelecimento de objetivos.

- Participação na tomada de decisões e no estabelecimento de objetivos.

- Redesenho de cargos para proporcionar maior desafio e responsabilidade.

\section{$\underline{\text { Teoria do Reforço }}$}

"A teoria do reforço ignora o estado íntimo do indivíduo e se concentra apenas no que ocorre a uma pessoa quando ela pratica uma determinada ação". Há quatro estratégias de comportamento organizacional reforço positivo, reforço negativo, punição e extinção.

\section{Teoria da Equidade}

A essência da teoria da equidade é a comparação feita pelas pessoas entre seus esforços e recompensas e os esforços e recompensas das outras pessoas que trabalham em situação semelhante. Na situação de trabalho ao que ele faz comparações entre o que ele recebe (recompensas que recebe) em relação ao que ele faz (contribuições que dá) e compara a sua equação de recompensas/ contribuições com a equação de recompensas/ contribuições das outras pessoas. Essas pessoas são tomadas como referências de comparação.

Porém quando um colaborador percebe uma ineqüidade irá ocorrer mudança em seu comportamento, tais como, redução do seu esforço no trabalho, reduz a qualidade de seu trabalho, ou mesmo saindo da organização.

\section{Teoria da Expectância}


Essa teoria foi proposta por Vroom em 1964, é uma das teorias mais aceitas a respeito de motivação, focalizando três relações:

- Relação entre esforço e desempenho;

- Relação entre desempenho e recompensa;

- Relação entre recompensas e objetivos pessoais.

Significando que um colaborador estará motivado a se esforçar caso ele acredite que seu esforço o levará a uma boa avaliação do desempenho, o que lhe trará recompensas da organização, tais como bônus, prêmio, promoção, entre outros, capaz de satisfazer seus objetivos individuais.

Essa teoria possui três aspectos básicos:

- Expectância o indivíduo sente-se capaz de alcançar o nível desejado de desempenho.

- Instrumentalidade o indivíduo compreende e confia que as recompensas virão como decorrência do desempenho alcançado.

- Valência o indivíduo compreende o valor dos possíveis retornos e recompensas.

Vivemos em um mundo onde em nenhuma outra época pudemos observar tantas mudanças. Isso contribui para desejarmos agir e nos comportar de maneira que consigamos atingir certos fins ou objetivos. Geralmente, atribuímos estes desejos à motivação, então acreditamos que devemos estar motivados.

Tentar estar motivado é muito difícil por causa das diferenças individuais e de como os indivíduos interagem com sua própria personalidade. Apesar disso, o tema motivação já 
nos dá uma sensação de bem-estar, porque está provado que, motivados, produzimos muito mais e melhor.

A motivação é uma espécie de força interna que emerge, regula e sustenta todas as nossas ações mais importantes. Percebemos a sua existência e sua natureza a partir da observação e da experiência de comportamentos. Ela se revela por meio de gestos e atitudes positivas e de boa aparência, entre outros.

Nossas maiores conquistas pessoais, com certeza, estão relacionadas à motivação. Nossa maneira de pensar reflete uma experiência de vida e influencia nossos comportamentos diante das pessoas com quem convivemos. É uma experiência interna, um fator gerador de satisfação. 


\section{LEVANTAMENTO DE NECESSIDADES}

Segundo teóricos motivacionais, mediante as oportunidades e estímulos adequados, as pessoas trabalham motivadas e com entusiasmo. O homem que vive em sociedade precisa e depende de outras pessoas para sobreviver, o que gera nele um conjunto de necessidades.

MILIONI (2001, p.9-10), dá uma definição de avaliação, validação e treinamento:

Avaliar significa submeter algo a um processo de análise normalmente determinado por parâmetros concretos ou referenciais.

Validar é reconhecer o valor esperado do objeto da análise efetuada, comparando a situação identificada, após uma ação de modificação do comportamento do público-alvo, aos fatos que levaram à realização do treinamento, a que se denomina, geralmente, de "carência".

Treinamento é a ação sistematizada de educação para a capacitação, o aperfeiçoamento e o desenvolvimento do indivíduo.

O levantamento de necessidades para este autor é a combinação dos três termos, o qual o processo de treinamento é o levantamento de dados que serão utilizados em benefício do próprio objetivo. 
Para a American Management Association (AMACON), geralmente o treinamento é fornecido a funcionários recém contratados, em alguns casos de funcionários, com tempo de casa, seja promovido ou caso a empresa adquira novos equipamentos, porém este ponto de vista cabe a empresa e ao supervisor de cada departamento valorizar o treinamento.

Os funcionários necessitam de novos estímulos para continuarem motivados com suas funções, além do que, com o treinamento, os interesses se renovam, podendo melhorar a qualidade do trabalho durante e após o treinamento.

No entanto quando o assunto é treinamento muitas dúvidas surgem a seu respeito, tais como:

- Há necessidade da obrigatoriedade;

- O que um treinamento tem a oferecer ao funcionário;

- Qual o programa de treinamento;

- Entre outras.

No que diz respeito à avaliação das necessidades comenta que o treinamento e desenvolvimento do funcionário tanto podem ser obrigatórios como opcional. Além disso, é necessário saber quais as áreas que mais precisam de treinamento. Algumas aplicações são sugeridas:

1. Treinamento para mobilidade ascendente. Contanto que seus funcionários entendam que a participação em um treinamento para uma tarefa de um nível mais avançado não garante automaticamente uma promoção, considere a possibilidade de dar a funcionários promissoras oportunidades de aprenderem trabalhos feitos por 
outros funcionários hierarquicamente superiores. Eles podem, então, participar e ajudar quando necessário. Dessa forma, estarão com certeza aumentando suas chances de serem promovidos quando surgirem vagas.

2. Treinamento horizontal. Funcionários cujas tarefas sejam semelhantes podem se beneficiar com o aprendizado das tarefas de seus colegas. Explique que isso os torna membros mais valiosos para o departamento e proporciona um melhor entendimento das metas gerais do departamento.

3. Equipamentos automatizados/ programas de software. Mesmo que o trabalho atual não requeira o uso de um computador ou software específico, tente estender os programas de treinamento formais a todos os membros do departamento que estiverem interessados em aprender. É muito importante permitir que os funcionários participem de programas de treinamento oficiais (de preferência com um instrutor em vez de um manual de treinamento), pois esta é a melhor forma para aprenderem tudo o que precisam saber. Quando você depende de um funcionário para ensinar uma lição a outro, você está garantindo a perda de informações importantes que a primeira pessoa ignorou ou não assimilou sem perceber a importância de transmiti-las para um colega.

4. Treinamento gerencial. Os supervisores normalmente não fornecem aos seus subordinados treinamento gerencial por terem medo de que esse treinamento os tire do cargo que ocupam, quando este não deve ser o caso. O treinamento gerencial básico ensina os participantes a enfrentar diversas situações dentro (e fora) do trabalho, tornando-os mais eficientes. Os supervisores também precisam aceitar o fato de que os funcionários receberão promoções que podem tirá-los do departamento e levá-los para novas áreas e que os próprios supervisores serão reconhecidos pela empresa por terem transferido um bom funcionário para um cargo que beneficia mais a organização.

5. Treinamento técnico. Os funcionários que demonstram aptidão para trabalhos técnicos que talvez não sejam necessários em seus cargos atuais também podem ser incentivados a crescer nesta área por meio de oportunidades de treinamento. Para isso, 
talvez seja preciso buscar treinamento fora da empresa, mas os benefícios podem superar o custo.

6. Treinamento para funcionários indispensáveis. Existem sempre dois ou três funcionários considerados tão bons naquilo que fazem que podem perder algumas oportunidades de treinamento, pois seus supervisores acreditam que não podem ser dispensados das tarefas desempenhadas naquele momento. Isso é injusto para com os funcionários, que podem acabar vendo o que está acontecendo e, provavelmente, sair da empresa em busca de maiores oportunidades. Um trabalho excelente precisa ser recompensado com mais do que simplesmente aumentos salariais e elogios. Esses funcionários precisam de oportunidades para crescer, se assim e desejarem.

O problema de encaixar o treinamento em um cronograma apertado sempre confunde supervisores. Contudo, não se trata de uma questão de encontrar a hora certa, mas sim de ajustá-la à perspectiva correta. Considere o treinamento tão importante quanto uma reunião de departamento e verá como é possível encaixá-lo no cronograma. Encontrar tempo para treinamento só é difícil quando ele é encarado como "opcional".

Quando os treinamentos têm duração de vários dias, talvez seja necessário dividir o departamento em grupos e fazer duas ou três sessões para que todo o departamento possa ser atendido. A não ser que o próprio curso exija uma dedicação maior, você pode instruir sessões de meio expediente para que os funcionários também possam cumprir algumas de suas obrigações diárias. Essa organização deve ser feita juntamente com o instrutor do curso.

Mas ainda hoje existe uma crise no setor de quem emprega e o empregado gerando uma insatisfação dos dois lados cuja síntese é: um não sabe como conseguir o que quer, e o outro não consegue gerenciar seus afazeres para atender as expectativas criadas. 
O fato é que, após o período de transição, do qual estamos próximos, as pessoas não terão emprego, terão trabalho, remunerado conforme os resultados.

Num passado não muito distante, indicava-se o tempo todo ao funcionário quais eram os seus afazeres. Hoje, ele deve buscar e apresentar resultados, o que gera estresse ao trabalhador, que ainda não se adaptou a isso.

É preciso se organizar para que o funcionário possa produzir o que mais importa. $\mathrm{O}$ sucesso das mudanças será mais rápido, e trará melhores resultados, quando forem atendidas quatro necessidades básicas do funcionário:

1)- física: carreira e finanças compensadoras e atraentes;

2)- sócio-emocional: relacionamentos mais equilibrados;

3)- mental: contínuo desenvolvimento e necessidade de aprender coisas novas;

4)- espiritual: satisfação interior, reconhecimento e sensação de realização na vida.

Os modernos instrumentos gerenciais têm trazido benefícios bastante tangíveis para as organizações, mas as rápidas mudanças no mundo fazem com que eles se tornem obsoletos em um curto espaço de tempo. Novos instrumentos gerenciais são então criados, e as pessoas se apressam em receber novos treinamentos, que podem se tornar estressantes e resultar em dificuldades no relacionamento social. Devido a isto, as pessoas tenderão a produzir menos e seu estado emocional terá influência direta na produção.

Para que isso não aconteça, dirigentes terão de aprender que o emocional de seus empregados influi na lucratividade do negócio. 
Deverá ser urgentemente adicionado ao treinamento gerencial um planejamento revolucionário para reeducar o ser humano no trabalho, dando-lhe condições para desenvolver os seus bens mais preciosos: seus valores e o amor ao próximo.

Os novos conceitos de capacitação emocional e de capacitação social introduzirão na empresa do futuro o ativo de diferenciação mais dramático: não bastará mais às empresas possuir quadros intelectualmente capazes, as organizações terão de ter indivíduos emocional e socialmente capazes e com a mais elevada capacitação nas suas relações interpessoais.

As empresas do futuro saberão que o desenvolvimento dos valores pessoais e interpessoais como objetivo estratégico lhes trará não só uma grande sinergia em suas equipes, como também do pessoal com os acionistas e com a sociedade. Isso significa que elas serão, certamente, mais lucrativas e mais produtivas.

Com isso, a gestão de pessoas vem se tornando o principal foco das grandes empresas. Apesar de persistirem em muitos ambientes técnicas obsoletas de recrutamento e de remuneração, hoje é difícil encontrar quem duvide da relação direta entre pessoas e resultados.

A escalada de executivos de Recursos Humanos $(\mathrm{RH})$, que antes tinham preocupações básicas com higiene e saúde das equipes, é visível pela massificação do conceito de remuneração variável, por exemplo.

A maioria das gerências percebe o sistema de remuneração como estratégico. Porém uma pesquisa da consultoria Pricewaterhouse Coopers com 1.055 corporações em 47 países verificou que $65 \%$ das empresas avaliam que esse impacto tem sido efetivo ou muito efetivo. 
No Brasil, esse índice é de $81 \%$. No entanto, alguns diretores de consultoria em capital humano, dizem que o crescimento dessa remuneração variável e da busca por modelos mais flexíveis, o que expressa o esforço para alinhar os interesses de executivos e de empregados aos dos acionistas.

Atualmente o dinheiro, por exemplo, já não é o principal fator de motivação. Os trabalhadores já não são meros assalariados, vivendo em função do salário que chega no fim do mês. Os trabalhadores são pessoas com sentimentos, desejos e ambições. Ninguém pode negar que luta por uma estabilidade econômica e financeira, mas as pessoas também se esforçam para conseguir realizarem-se profissionalmente. Mais importante que o pagamento no final do mês, é a satisfação que se pode levar para casa, ao final de cada dia, sabendo que se desempenhou bem as funções que estavam atribuídas, e que esse desempenho irá ser reconhecido.

É este o melhor prêmio que o trabalhador pode levar para casa. Idealmente, a remuneração deveria acompanhar o bom desempenho, como forma de recompensa e reconhecimento. Mas mesmo que tal não aconteça, o trabalhador tem consciência das suas capacidades e habilitações, o que faz com que não desanime, pois tem sempre a possibilidade de oferecer os seus serviços a outras organizações que se disponham a valorizar as suas capacidades. As organizações não devem apenas contratar estrelas do mercado, mas sim de desenvolver os talentos de funcionários internos.

Para LUNDIN, PAUL \& CHRISTENSEN (2000), é possível trabalhar melhor, fazendo dele um ambiente feliz de trabalho, para que esperar até a aposentadoria já que passamos tanto tempo de nossas vidas nele, se você pode transformá-lo em um local agradável com apenas simples atitudes, deixando que energias fluam pelo ambiente.

O ambiente em que vivemos interfere em nossa motivação, pois é através dele que conseguimos satisfazer essas necessidades. Mas, apesar disso, só nós temos a capacidade de nos automotivar, se desenvolvermos atitudes e pensamentos positivos, melhorando nossa auto-estima, nos autoconhecendo, observando nossos sentimentos 
e emoções, cuidando do nosso corpo, vivendo em um ambiente saudável e útil, desenvolvendo relacionamentos motivadores, assumindo responsabilidades, procurando solucionar os nossos problemas, definindo prioridades, planejando, atingindo metas e objetivos, aceitando desafios, tendo iniciativa, sendo otimistas, compartilhando conhecimentos e estando abertos a mudanças. Sabendo utilizar a motivação, esta força interior, estaremos melhorando a nós mesmos e valorizando mais nossa vida. Tais como:

- Escolher a própria atitude - o indivíduo pode escolher por começar seu dia com o pé direito ou não, apesar dos problemas. Hoje em dia quem não tem problemas? É uma questão de atitude.

- Brinque - um restaurante pode se transformar em um playground para adultos.

- Alegre o dia das pessoas - o cliente é convidado a participar das brincadeiras. O local tem uma atmosfera convidativa.

- Faça-se presente - não ficar distraído, nem pendurado ao telefone, é observar os clientes/ pessoas e interagir com elas, conversar como se fosse um amigo que sumiu durante muito tempo.

\subsection{Pesquisa destinada a testar a hierarquia das necessidades}

CLONINGER (1999), com base na teoria de maslow apresentada a seqüência das cinco necessidades obedecendo à ordem por ele descrita.

Sendo de se esperar que a fome e a pobreza impedem o funcionamento mais elevado, mas muitos exemplos contrariam essa suposição. Através de observações constatou que pessoas em situações econômicas calamitosas que, em aparente contradição com o conceito de uma hierarquia das necessidades, pareciam funcionar nos níveis 
elevados do potencial humano. Um exemplo foi os campos de concentração nazistas, que apesar de todas a suas atrocidades, não fizeram com que todos os prisioneiros regredissem aos níveis mais baixos do funcionamento humano, como a teoria hierárquica de Maslow insinuara. Pessoas cometem suicídio, comprometendo claramente suas necessidades de segurança; pessoas famintas se recusam a praticar atos de canibalismo ou a comer vacas sagradas quando suas crenças religiosas não permitem esses atos. Soldados morrem por causas políticas. A partir desses exemplos, é sugerido a alguns que a hierarquia das necessidades deveria ser abandonada.

Baseando-se em dados de questionários aplicados a estudantes, houve uma melhor formulação do modelo, o qual teria apenas três níveis de necessidade: fisiológico, pertencimento e auto-realização. As outras duas necessidades estima e segurança, não se encaixaram na ordem prevista por Maslow quando os estudantes compararam quais pares de duas satisfação relacionadas com necessidades eles poderiam descartar. 


\section{METODOLOGIA}

A empresa $X$ é um empreendimento brasileiro do ramo de Alimentos \& Bebidas ( $\&$ \& $B$ ). A empresa sempre se caracterizou pela preocupação com o bem estar de seus clientes. Tendo como formação três sócios que se encontra no mercado brasiliense há sete anos. O que lhe proporcionava um clima constantemente sadio de relação, porém neste período muitas casas do ramo fecharam e muitas também abriram.

Contudo os concorrentes inovadores do ramo que chegam, vêm com novidades do mercado, diferenciais competitivos, ânimo novo, equipe inicialmente querendo mostrar eficiência. O que ameaça a situação competitiva da empresa $X$, que não investiu em seus funcionários.

A empresa X, localizada em Brasília, Distrito Federal. Conta com cerca de 83 funcionários. $E$ as experiências realizadas visavam detectar que, além dos sócios o empreendimento possui o que chamam de grupo de investidores, que ao longo desses anos, alguns deles vêem gerenciando por algum período, houve várias mudanças desses gestores e o atual possui planos para aumentar o faturamento e interesse de seus funcionários.

Em 2003, com a colaboração do gestor, ele definiu objetivos e metas para a empresa tais como: a busca de um crescimento estruturado, profissionalização da empresa; 
alcance da excelência na prestação de serviço; ser a melhor e maior franquia da rede; tornar-se líder no mercado de entretenimento da região centro-oeste e aumentar a rentabilidade da empresa; e como metas, aumentar o faturamento médio dos próximos seis meses em 100\%; desenvolver um novo ambiente de trabalho, com uma estrutura organizacional bem definida e prática, reduzindo os esforços na realização das atividades diárias; fechar 0 ano com lucro mínimo pré-estabelecido; eliminar desperdício, o custo financeiro da empresa; trabalhar com uma antecedência de planejamento; oferecer e criar diferenciais.

Mas devido à ausência de uma política de Recursos Humanos $(\mathrm{RH})$ por parte dos franqueados, que segundo ODELIUS, atua na sociedade por meio da procura de relações justas e de melhores condições e qualidade de vida, não se restringindo ao contexto interno da organização. Deve equilibrar os objetivos da empresa e de seus funcionários, proporcionando condições satisfatórias de trabalho, balanceando ambos os interesses, empregados e empregadores.

Na proposta de crescimento da empresa não foi levado em consideração o treinamento, a profissionalização, as necessidades, planos de incentivos, plano de carreira salarial dos funcionários, para que estes acompanhem o crescimento da empresa e sintam participativos no crescimento, pois sem a participação deles não é possível alcançar os resultados esperados, que é a "satisfação dos clientes revertida em lucro para a empresa".

Atualmente a empresa opera com dados e não com informações, não possui uma estrutura organizacional bem definida com uma equipe bem capacitada, possui problemas na comunicação, falta de interação entre os componentes desta e muitas ações por improviso, o que prejudica a qualidade dos produtos e serviços.

O organograma da empresa está dividido em seis setores, setor de marketing, financeiro, administrativo, operacional noturno, operacional diurno e cozinha, os quais devem se dirigir diretamente ao gestor. E o chefe de cada setor é responsável pelo 
desempenho de seu departamento supervisionando e supostamente motivando seus funcionários, que são de certa forma colaboradores para o alcance e sucesso do objetivo da empresa.

Os estudos básicos efetuados tiveram duas fases:

- Programa de Entrevista

- Sala de observações da montagem de terminais

A primeira experiência teve como finalidade à realização de um estudo do nível de stress no trabalho, decorrente dos efeitos gerados por mudanças de horários ou introdução de intervalos de descanso no período de trabalho.

Foram selecionados para a experiência trinta e um funcionários que trabalham no período da manhã, já que durante este período ocorreram ligeiras modificações nos ritmos de produção e de qualidade no atendimento. Os funcionários encontram-se nos diversos setores da empresa, realizando as mais diversas tarefas tais como: telefonista, auxiliar administrativo, caixa, estoquista, auxiliar de cozinha, saladeira, chefe de cozinha, cozinheiro, sub chefe, barman, serviços gerais, maitre, garçons e garçonetes.

\section{Conclusões}

- Há um ambiente que gera conflitos devido à pressão e a concorrência entre os próprios funcionários.

- Há temor ao supervisor.

- O grupo não desenvolve liderança e objetivos comuns. 


\section{Entrevistas}

Foram entrevistados todos os funcionários da empresa, cujo turno foi o vespertino. $\mathrm{O}$ objetivo foi investigar os motivos que levavam os funcionários a adotarem uma postura tão diferente nos seus departamentos e entre seus colegas de trabalho. A partir desta fase as observações passaram a ter um enfoque nas relações humanas.

O resultado esperado pelo programa seria: o aumento da produtividade dos operários, a melhora na prestação de serviços e a melhora na comunicação entre um departamento e outro. A melhoria desses resultados seria atribuída a um sentimento de importância desencadeado pelo programa. No caso dos supervisores, o conhecimento dos interesses dos funcionários seria o responsável pelas sensíveis mudanças no modo de supervisão.

As entrevistas inicialmente tinham duração de meia hora e eram pautadas em perguntas preestabelecidas, de acordo com o questionário aplicado. Com o decorrer do tempo, percebeu-se que além de muito curtas, as entrevistas não possibilitavam que os operários falassem de todos os seus problemas, aflições e medos, a partir daí, foi possível notar que o processo deveria ser mais longo e tendo como principal característica uma conversa informal entre supervisor e operário.

O resultado das entrevistas foi à constatação de que a maioria dos funcionários agia e pensava de modo egoísta, pois não havia um trabalho em equipe. Havia detalhes que incomodavam de maneira excessiva algumas pessoas, o que acabava por interferir no ambiente de trabalho. Um exemplo foi relatado por um dos funcionários: seu chefe possuía um ar de superioridade, ao qual gostava de deixar claro até mesmo as diferenças salariais, e isso o fazia sentir-se inferiorizado, de que seu trabalho não era digno. 
A conclusão da avaliação foi possível constatar que os fatores psicológicos alteravam de maneira significativa o comportamento dos funcionários. Ao mesmo tempo, que os funcionários mostrassem à direção quais suas angustias mais freqüentes, a partir daí, elas podem ser estudadas e seus efeitos minimizados.

\section{Sala de Observações de Montagem de Terminais}

Esta seria uma proposta para ser entregue ao gestor, caso tenha um maior interesse com o que acontece com os funcionários quando ele não está por perto. Dividem-se os funcionários em dois grupos e cada grupo é escolhido aleatoriamente - de maneira que possam realizar suas funções e que possam trabalhar em uma sala especial com idênticas condições de trabalho do departamento. Haveria um observador dentro da sala e um entrevistador que ficava do lado de fora e que estaria entrevistando esporadicamente aqueles funcionários. Essa experiência poderia ocorrer em um período de um ano, visando analisar a organização informal dos operários.

A forma de pagamento continuaria a mesma, salarial e os 10\% (dez porcentos), sendo que com a melhora do atendimento e dos serviços prestados poderia haver uma maior demanda de clientes, que estando satisfeitos poderiam fazer um marketing boca a boca e até tornar um cliente assíduo.

Assim que estivesse familiarizado com o grupo experimental, o observador poderá constatar como funciona o dia a dia dos funcionários. Relatando e verificando que os funcionários podem apresentar certa uniformidade de sentimentos e solidariedade grupal. Geralmente o grupo desenvolve métodos para assegurar suas atitudes, considerando delator o membro que prejudica algum companheiro e pressionam os mais rápidos para "estabilizarem" a sua "produção", através de punições simbólicas. Essa fase permite o estudo das relações entre a organização informal dos empregados e a organização formal da empresa $X$. 


\section{Conclusões do estudo de caso}

O estudo de caso permitiu o delineamento dos princípios básicos da Escola das Relações Humanas. Em destaque as principais conclusões.

Nível de Produção seria Resultante da Integração Social e não da capacidade física ou fisiológica do empregado (como afirma a teoria clássica), mas por normas sociais e expectativas que o envolvem. É a capacidade social do trabalhador que estabelece seu nível de competência e de eficiência. Quanto mais integrado socialmente no grupo de trabalho, tanto maior a sua disposição de produzir.

Comportamento Social dos Empregados se apóiam totalmente no grupo. Os trabalhadores não reagem isoladamente como indivíduos, mas como membros do grupo, apesar de haver sub grupos, grupos informais, entre os próprios funcionários. 0 grupo pune o indivíduo que sai das normas grupais.

Grupos informais - A empresa passaria a ser visualizada como uma organização social composta de diversos grupos sociais informais. Esses grupos informais definem suas regras de comportamento, suas formas de recompensas ou sanções sociais, seus objetivos, sua escala de valores sociais, suas crenças e expectativas. Delineando com essa teoria o conceito de organização informal.

As Relações Humanas são as ações e atitudes desenvolvidas pelos contatos entre pessoas e grupos. Os indivíduos dentro da organização participam de grupos sociais e mantém-se uma constante interação social. Relações Humanas são as ações e atitudes desenvolvidas pelos contatos entre pessoas e grupos.

Cada indivíduo é uma personalidade diferenciada que influi no comportamento e atitudes uns dos outros com quem mantém contatos. É exatamente a compreensão da 
natureza dessas relações humanas que permite ao administrador melhores resultados de sua equipe.

A importância da Descrição dos Cargos. A maior especialização e, portanto a maior fragmentação do trabalho não é a forma mais eficiente dele. Através da descrição é possível definir as funções a serem elaboradas por cada funcionário para que não haja trocas, que podem gerar a monotonia, insatisfação, contrariando a política da empresa.

Ênfase nos aspectos emocionais. Os elementos emocionais, não planejados e mesmo irracionais do comportamento humano passam a merecer atenção especial por parte de quase todas as grandes figuras da Teoria das Relações Humanas. 


\section{RELAÇÕES HUMANAS}

Com o advento da Teoria das Relações Humanas, uma nova linguagem passa a dominar o repertório administrativo: Fala-se agora em motivação, liderança, comunicação, organização informal, dinâmica de grupo etc. Os princípios clássicos passam a ser duramente contestados. O engenheiro e o técnico cedem lugar ao psicólogo e ao sociólogo. O método e a máquina perdem a primazia em favor da dinâmica de grupo. A felicidade humana passa a ser vista sob um ângulo completamente diferente, pois o homoeconomicus cede lugar ao homem social. A ênfase nas tarefas e na estrutura é substituída pela ênfase nas pessoas.

O quadro abaixo relaciona as principais diferenças entre a teoria clássica e a teoria das relações.

\begin{tabular}{|l|l|}
\hline Teoria Clássica & Teoria das Relações \\
\hline Trata a organização como uma Máquina & $\begin{array}{l}\text { Trata a organização como um grupo de } \\
\text { pessoas }\end{array}$ \\
\hline Enfatiza as tarefas ou a tecnologia & Enfatiza as pessoas \\
\hline Inspirada em sistemas de engenharia & Inspirada em sistemas de psicologia \\
\hline
\end{tabular}




\begin{tabular}{|l|l|}
\hline & \\
\hline Autoridade Centralizada & Delegação plena de autoridade \\
\hline Linhas claras de autoridade & Autonomia do empregado \\
\hline Especialização e competência Técnica & Confiança e abertura \\
\hline Acentuada divisão do trabalho & $\begin{array}{l}\text { Enfase nas relações humanas entre as } \\
\text { pessoas }\end{array}$ \\
\hline $\begin{array}{l}\text { Confiança nas regras e nos } \\
\text { regulamentos }\end{array}$ & Confiança nas pessoas \\
\hline Clara separação entre linha e staff & Dinâmica grupal e interpessoal \\
\hline
\end{tabular}

Comunicação

Com as experiências sobre liderança, os pesquisadores passam a concentrar sua atenção nas oportunidades de ouvir e aprender em reuniões de grupo e notar os problemas das comunicações entre grupos de empresas. Passou-se a identificar a necessidade de elevar a competência dos administradores através do trato interpessoal, no sentido de adquirirem condições de enfrentar com eficiência os complexos problemas de comunicação, bem como de adquirir confiança e franqueza no seu relacionamento humano.

Neste sentido, a Teoria das Relações Humanas criou uma pressão sensível sobre a Administração no sentido de modificar as habituais maneiras de dirigir as organizações. 
O enfoque das relações humanas adquiriu certa imagem popular cujo efeito líquido foi compelir os administradores a:

- Assegurar a participação dos escalões inferiores na solução dos problemas da empresa.

- Incentivar maior franqueza e confiança entre os indivíduos e os grupos nas empresas.

A comunicação é uma atividade administrativa que tem dois propósitos principais:

- Proporcionar informação e compreensão necessárias para que as pessoas possam conduzir-se nas suas tarefas.

- Proporcionar as atitudes necessárias que promovam motivação, cooperação e satisfação no cargo.

Estes dois propósitos, em conjunto, promovem um ambiente que conduz a um espírito de equipe e um melhor desempenho nas tarefas.

Para a Teoria das Relações Humanas, a comunicação é importante no relacionamento entre as posições e no conhecimento e na explicação aos participantes inferiores das razões das orientações Tomadas.

\section{Organização Informal}

Existem padrões de relações encontrados na empresa, mas que não aparecem no organograma. Encontramos amizades e antagonismos, indivíduos que se identificam com outros, grupos que se afastam de outros e uma grande variedade de relações no trabalho ou fora dele e que constituem a chamada organização informal. Essa 
organização informal desenvolveu-se a partir da interação imposta e determinada pela organização formal. Os padrões informais de relações são extremamente diversos quanto à forma, conteúdo e duração e nos mostram que nem sempre a organização social de uma empresa correspondente exatamente ao seu organograma.

\section{Dinâmica de Grupo}

FAILDE (2001), faz uma introdução a respeito da dinâmica de Grupo, o qual foi fundada por Kurt Lewin a Escola da Dinâmica de grupo desenvolve uma proposição geral de que o comportamento, as atitudes, as crenças e os valores do indivíduo baseiam-se firmemente nos grupos aos quais pertence.

Dinâmica de grupo é a soma de interesses dos componentes do grupo, que pode ser ativada através de estímulos e motivações, no sentido de maior harmonia e aumento do relacionamento. As relações existentes entre os membros de um grupo recebem o nome de relações intrínsecas. O chefe deve estar atento às relações entre os componentes do grupo, deve procurar desenvolver o sentido de equipe, estimulando os seus elementos ao respeito e à estima recíprocos. As reuniões periódicas, as palestras, as conversas informais com os componentes do grupo colaboram para que estes resultados sejam alcançados.

Segundo esta Escola os grupos podem participar do processo de mudança em pelo menos três perspectivas diferentes, a saber:

O grupo como instrumento de mudança, nesta perspectiva, o grupo aparece como fonte de influência sobre seus membros. Os esforços para mudar o comportamento podem encontrar apoio ou resistência do grupo sobre os seus membros.

O grupo como meta de mudança, nesta perspectiva, para mudar o comportamento de indivíduos, pode-se tornar necessário mudar os padrões do grupo, seu estilo de 
liderança, seu ambiente emotivo etc. Muito embora a finalidade possa ser a mudança do comportamento de indivíduos, o grupo torna-se a meta da mudança.

O grupo como agente de mudança. Certas mudanças de comportamento podem ser provocadas somente através de esforços organizacionais de grupos que atuem como agentes de mudança

\section{$\underline{\text { Criticas }}$}

Após o domínio da Teoria das Relações humanas por cerca de mais de uma década, ao final dos anos 50, entrou em declínio, passando a ser intensamente criticada, a tal ponto que suas concepções passaram a ser profundamente revistas e alteradas. O qual cita as principais críticas à teoria:

- Oposição cerrada à Teoria Clássica;

- Inadequada visualização dos problemas das relações industriais;

- Concepção ingênua e romântica do operário;

- Limitação do campo experimental;

- Parcialidade das conclusões;

- Ênfase nos grupos informais;

- Enfoque manipulativo das relações humanas. 


\section{CONSIDERAÇÕES FINAIS}

Um setor de RH seria de extrema importância, pois este estaria encarregado de todo o processo de seleção, treinamento, desenvolvimento, contratação, motivação dos funcionários. Seria um departamento com critérios de admissão e demissão de funcionários, o que em alguns setores não há critério algum, apenas uma simples conversa com o gerente do departamento e pronto funcionário contratado, provavelmente esta seja uma das causas da alta rotatividade, não há critérios e depois dispensam.

Um bom gestor é aquele que consegue gerir as aptidões e competências que se movem na empresa, mantendo interditamente a motivação. Se o gestor adaptar os seus métodos de gestão às capacidades e talentos revelados pelos seus colaboradores, haverá uma resposta muito mais positiva por parte dos mesmos. Convém não esquecer que trabalhadores motivados e reconhecidos aumentam o nível de qualidade e quantidade de desempenho, e conseqüentemente, aumenta a produção. 


\section{REFERÊNCIAS BIBLIOGRÁFICAS}

- AMERICAN MANAGEMENT ASSOCIATION. Como Motivar Para Obter desempenho Máximo. Rio de Janeiro: Campus, 2000.

- BREI, Zani Edna Andrade. Motivações das Atitudes de Pesquisadores em Relação à Avaliação do Desempenho e Premiação por Resultados no Trabalho. Brasília: [s.n.], 2002.

- CAMPOS, Luiz Fernando de Lara. Métodos e Técnicas de Pesquisa em Psicologia. Campinas, SP: Alínea, 2000.

- CHIAVENATO, Idalberto. Administração nos Novos tempos. Rio de Janeiro: Campus, 1999.

- ClONINGER, Susan C. Teorias da Personalidade. São Paulo: Martins Fontes, 1999.

- DAVIDOFF, Linda L. Introdução à Psicologia. São Paulo: Mc Graw-Hill do Brasil, 1983. 
- FAILDE, Izabel. Dramatização e Dinâmica de Grupo. In: LAKATOS, Eva Maria \& MARCONI, Marina de Andrade (org.). Fundamentos de Metodologia Científica. 4. ed. São Paulo: Atlas, 2001.

- LUNDIN, S. C.; PAUL, H.; CHRISTENSEN, J. Peixe! como motivar e gerar resultados. 3. ed. Rio de Janeiro: Campus, 2000.

- MILIONI. Integrando o Levantamento de Necessidades com a Avaliação e Validação do Treinamento. In: LAKATOS, Eva Maria \& MARCONI, Marina de Andrade (org.). Fundamentos de Metodologia Científica. 4. ed. São Paulo: Atlas, 2001.

- ODELIUS, Catarina Cecília. Gestão da Hospitalidade III. Brasília: Universidade de Brasília, [2003?]. 